Available online at GSC Online Press Directory

GSC Biological and Pharmaceutical Sciences

e-ISSN: 2581-3250, CODEN (USA): GBPSC2

Journal homepage: https://www.gsconlinepress.com/journals/gscbps

(RESEARCH ARTICLE)

\title{
Diversity and ecology of phytoplankton of Batika river (Yabassi, Cameroon)
}

\author{
Ndjouondo Gildas Parfait 1, *, Muyang Rosaline Fosah 1, Nouck Alphonse Erve 2, Nwamo Roland Didier 3 , \\ Fotso ${ }^{1}$, Tita Margaret Awah ${ }^{1}$ and Dibong Siegfried Didier ${ }^{4}$ \\ ${ }^{1}$ Department of Biology, Higher Teacher Training College, The University of Bamenda, P.O. Box 39 Bambili, Cameroon. \\ 2 Department of Biological Sciences, Faculty of Sciences, The University of Bamenda, P.O. Box 39 Bambili, Cameroon. \\ ${ }^{3}$ Department of aquaculture, Institute of Fishery Sciences, The University of Douala, B.P. 2701 Douala, Cameroun. \\ ${ }^{4}$ Department of Botany, Faculty of Science, University of Douala, P.O. Box 24157 Douala, Cameroon.
}

Publication history: Received on 04 May 2020; revised on 18 May 2020; accepted on 20 May 2020

Article DOI: https://doi.org/10.30574/gscbps.2020.11.2.0126

\begin{abstract}
Human activities increasingly accentuate the imbalance of hydrosystems. The aim of the study is to contribute to the knowledge of phytoplankton and some physicochemical parameters related to the Batika river with a view to proposing methods of monitoring for sustainable production of carp fry. Sampling took place monthly from March, 2019 to February, 2020. Physicochemical parameters were measured in situ and in the laboratory. The pelagic area was sampled at 7 identified stations along the river. Two groups were observed according to the physicochemical parameters made up of exclusive species. Group I bringing stations 1, 2 and 3 upstream together; group II bringing stations 5, 6 and 7 downstream closer together. Station 4 is considered a transition station between upstream and downstream. Specific richness of phytoplankton amounts to 6 classes divided into 28 genera and 34 species. The most represented class is Chlorophyceae (36\%). The least represented class is Ulvophyceae (1\%). Shannon-Weaver diversity index ranges from 3.24 (station 7) to 1.76 (station 4). Specific richness is not very variable from one station to another. The most common types of the study site are Closterium and Micrasterias. Physicochemical parameters show that the Batika river is less polluted. These results show that the Batika river has low phytoplankton richness and good quality water. Monitoring this river would maintain its ecological status for sustainable production of carp fry.
\end{abstract}

Keywords: Batika river; Human activities; Hydrosystem; Physicochemistry; Phytoplankton

\section{Introduction}

Rivers have always served as a source of drinking water or irrigation, as a fishing site. They are also used for the disposal of waste produced by human activities [1]. Rivers are blessed with exceptional animal and plant biodiversity. Algal biodiversity is a component of aquatic flora. Algae have different morphologies: solitary or colonial unicellular forms. They are distinguished from higher plants by a relatively simple organization: thallus without leaves, stems or roots [2].

Batika river runs through the city of Yabassi. It is home to a large fauna of carp and tilapia fry feeding the Nkam river, considered today as an ecological niche [3].

However, population growth in the district of Yabassi is a real statement. To this end the will of the Institute of Fishery Sciences at Yabassi is to seek strategies for the management of aquatic ecosystems. In the same vein, the Ramsar Convention (Convention on Wetlands of International Importance) promotes the wise use of wetlands and their resources. In this dynamic, the structure of the phytoplankton population and the stability of aquatic ecosystems has been the subject of numerous studies in the marine and lake environments [4] [5] [6] [7]. Kemka et al. [8] establish the relationship between biodiversity and the functioning of ecosystems which remains a fundamental ecological issue. It

\footnotetext{
* Corresponding author: Ndjouondo Gildas Parfait
}

Copyright (C) 2020 Author(s) retain the copyright of this article. This article is published under the terms of the Creative Commons Attribution Liscense 4.0. 
is essential to know the abiotic factors that affect aquatic ecosystems and their durability in time and space because the degradation of the water resource results essentially from point and diffuse pollution, and the modification of the environmental characteristics [1]. For this purpose, traditional physicochemical analyze provide, only occasional information on the state of the environment, but an overall integration of water quality over time can be obtained by analyzing aquatic organisms, which take account biotic and abiotic variations of the environment over long periods of time [1]. In this context, there is no database of locations of phytoplankton biodiversity in the Batika river. Hence the need for work on the phytoplankton diversity of the Batika river, the main food source of zooplankton. The aim of this study is to contribute to knowledge of phytoplankton and some physicochemical parameters related to the Batika river with a view to proposing monitoring methods for sustainable production of carp fry.

\section{Material and methods}

\subsection{Presentation of the study area}

Yabassi $\left(9^{\circ} 50^{\prime}-10^{\circ} 10^{\prime} \mathrm{N}\right.$ and $4^{\circ} 20^{\prime}-4^{\circ} 40^{\prime} \mathrm{E}$, elevation $\left.20 \mathrm{~m}\right)$ is the capital of the Nkam department. It is part of the northern equatorial climate zone. Climate is subequatorial tropical looking with two seasons: A dry season that runs from December to March and a rainy season that runs from March to December. The Maximum rainfall is in July and August [9]. Average annual temperature is $26.4{ }^{\circ} \mathrm{C}$. Precipitation shows that Yabassi is rainy with rainfall over 9 months. Average annual rainfall is $360.83 \mathrm{~mm}$. Average annual humidity is $78.3 \%$, average annual evaporation is $50.6 \%$ and in the end, average annual insolation is $109.6 \%$. Prevailing wind carries the monsoon [10] (Fig. 1).

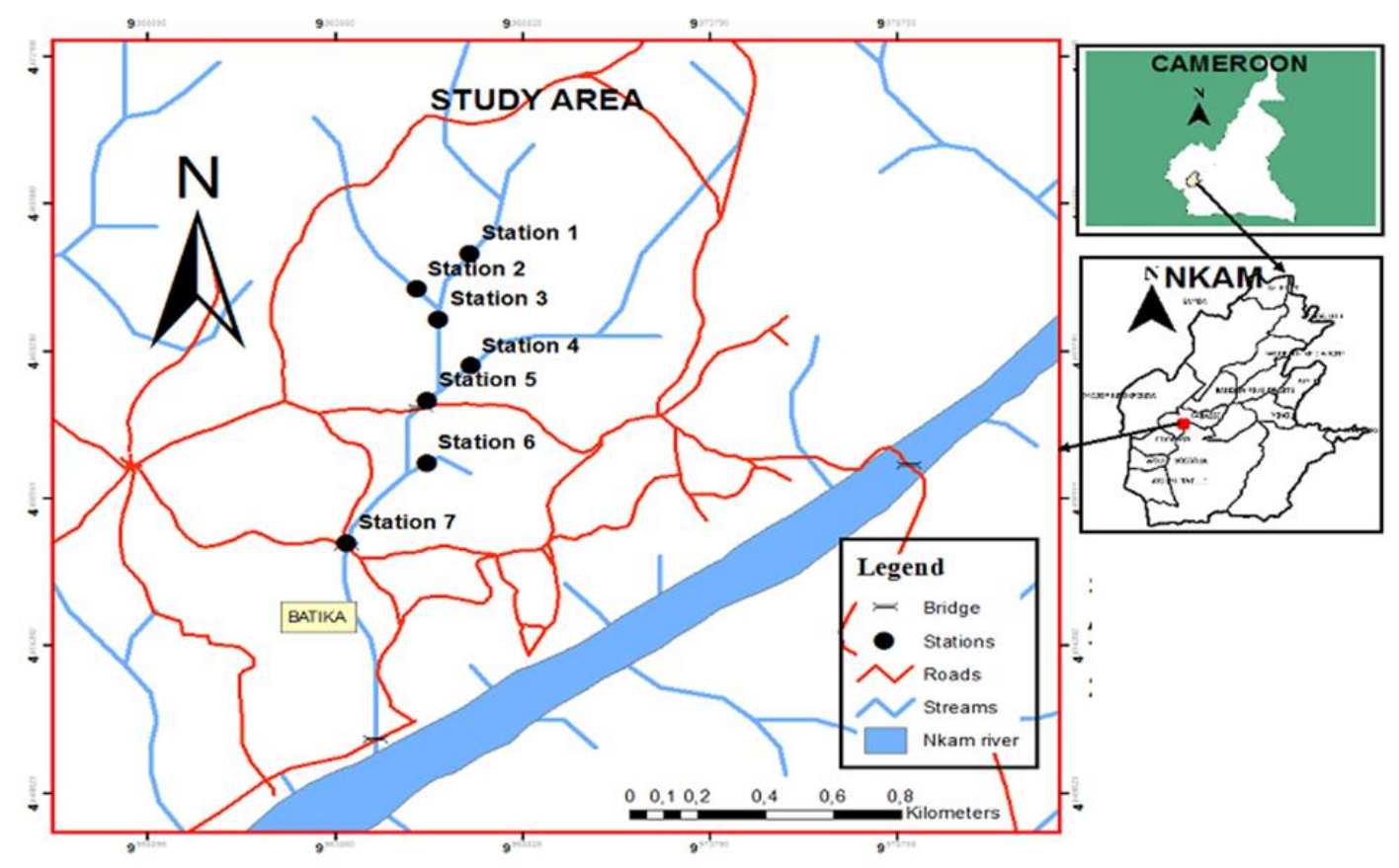

Figure 1 Location map of the study area [11] modified.

The soils are of ferralitic type with dominant sandy structure. They are sedimentary soils on recent alluvium with low water holding capacity [9]. Relief is stepped at an elevation of 20 to $1,000 \mathrm{~m}$ from the Wouri estuary to the upland rim. It is a gently undulating terrain but very rugged with a succession of small narrow valleys, hills and shallows. This relief is responsible for the isolation of this area thus making accessibility very difficult [11]. Department of Nkam is watered by a watercourse called Nkam. It is the outlet of many rivers such as the Batika river. Vegetation of Yabassi is a littoral type forest characterized from the floristic point of view by the dominance of Bongossi (Lophira alata), Bidou or Azouga (Sarcoglottis sp.), Nkokom (Cynometra hankei). Fauna of Yabassi is made up of an important terrestrial and aquatic diversity. Aquatic fauna according to oral sources, would contain several families of species of which the most abundant are: Mormyridae, Cyprinidae, Anabantidae, Cichlidae, Clariidae and Claroteidae with Chrysichthys nigrodigitatus (Machoiron) as dominant species. According to [11], population of Yabassi is estimated at nearly 12,999 habitants in 2005 with a growth rate of $1.72 \%$. It is aging and the class of 18 to 28 year olds is in second place. This population is made up of more native people than of non-native people who have gone to their occupations or for study purposes. It 
is used for activities such as: agriculture, fishing, hunting, stock breeding and petty trading. Fishing occupies $20 \%$ of the assets in this locality. While, 4549 (35\%) people are involved in agricultural activities of the total population [12].

\subsection{Period of sampling}

Study was conducted from March, 2019 to February, 2020 with monthly sampling at the Batika river where 7 stations were sampled upstream, in the middle and downstream.

\subsection{Measurement of physicochemical parameters}

Physicochemical parameters were measured between 08:00 and 11:00 at each station using 0.5 L polyethylene bottles and stored at $-4^{\circ} \mathrm{C}$ in a cooler for analysis of nitrates, total phosphorus and BOD 5 at the laboratory. Dissolved oxygen was measured in situ by a WTW oxymeter. Ambient temperatures, conductivity, total dissolved solids, salinity and water $\mathrm{pH}$ were measured by an OAKTON brand $\mathrm{pH} / \mathrm{TDS} / \mathrm{COND} / \mathrm{Salt} / \mathrm{T}$ multiparameter from HANNA instruments. Water velocity was measured using a rope equipped with a float, launched into water and a stopwatch for measuring the time traveled by the float over a distance of $10 \mathrm{~m}$. Following formula made it possible to determine the velocity (V): $\mathrm{V}=\frac{d}{t}$ with $\mathrm{V}$ in $\mathrm{m} / \mathrm{s}, \mathrm{d}=$ distance in $\mathrm{m}$ and $\mathrm{t}=$ time in $\mathrm{s}$. Average depth was measured at each station using a graduated stick located on both banks and in the middle of the stream.

\subsection{Qualitative and quantitative sampling of phytoplankton}

Plankton net made it possible to filter $200 \mathrm{~L}$ of water. The contents were dumped in a $50 \mathrm{~mL}$ pillbox labeled at each station. Each sample was fixed with formalin at $5 \%$ of its volume, homogenized and kept in the dark.

\subsection{Phytoplankton qualitative analysis}

In the laboratory, subsamples were made. After sedimentation of the individuals for $24 \mathrm{~h}$, a drop of each sample was mounted between slide and coverslip and observed under OLYMPUS microscope. Two preparations were made for each sample. The identifications were made directly. But photographs were made for hard-to-identify individuals for more details about the measurements. The following identification keys were used: [13] [2] [14] [15] [16] [17] [18] [19] [20] [21] [22].

\subsection{Phytoplankton quantitative analysis}

After depositing the sampled jars, homogenization was performed. $10 \mathrm{~mL}$ sub samples of Becher were made. After stirring each beaker left at rest and in the dark for 24 hours, $1 \mathrm{~mL}$ was taken by a micropipette and then poured into the counting slide of Malassez. OLYMPUS brand microscope was used for counting individuals. Counting unit of the filaments was set at $100 \mu \mathrm{m}$ as 1 individual. Colonies and coenobes were considered as 1 individual [23].

\subsection{Determination of biological parameters}

\subsubsection{Shannon-Weavers' Diversity Index}

Shannon-Weavers' index $\left(\mathrm{H}^{\prime}\right)$ was determined by the following formula: $\mathrm{H}^{\prime}=-\sum \mathrm{Pi} \times \log _{2} \mathrm{Pi}$; with $\mathrm{Pi}=\mathrm{ni} / \mathrm{N}(\mathrm{Pi}=$ presence index, $\mathrm{ni}=$ number of species $\mathrm{i}$ in the station and $\mathrm{N}=$ total number of species in the station).

\subsubsection{Pielou's regularity index}

Pielou's regularity index $(\mathrm{R})$ was used to report the relative abundance of each species, the distribution of taxa and the quality of stand organization. Its formula is: $\mathrm{R}=\mathrm{H}^{\prime} / \mathrm{H}^{\prime} \max$, where $\mathrm{Hmax}=\log _{2} \mathrm{~S}(\mathrm{~S}=$ number of species of the medium and Hmax = index of maximum diversity). $\mathrm{R}$ is 0 when only one species dominates and 1 when all species have the same abundance.

\subsubsection{Sorensen's Similarity index}

Let $\mathrm{A}$ and $\mathrm{B}$ be two media, $\mathrm{c}=$ number of species common to both media; $\mathrm{a}=$ number of species present in the medium $A$ and $b=$ number of species present in the medium B. Sorensen's similarity index (S) varies from 0 (lack of similarity) to 1 (identical media), $S=2 c /(2 c+a+b)$. 


\subsubsection{Density of Phytoplankton}

Density calculation (D) is expressed by the formula: $\mathrm{D}=\mathrm{Ni} \times 1000 \times \mathrm{V} / \mathrm{V}$, with $\mathrm{D}$ in number of individuals per liter (ind/L), $\mathrm{Ni}$ = number of individuals for the species considered, $\mathrm{V}=$ volume of the sample, $\mathrm{v}=$ volume of the subsample counted in $\mathrm{mL}$ and $1000=$ conversion factor.

\subsection{Statistical analyzes of the data}

Principal Component Analysis (PCA) was used to order stations based on abiotic parameters. Correspondence Factor Analysis (CFA) has been applied to illustrate correlations between stations in functions of different species. These analysis were carried out by the software XLSTAT 2014. The Software Past 3 allowed the construction of the diagrams and the calculation of the indices of diversity; Excel of the Microsoft Office 2010 package for data processing; GRAPHPAD Prism 5 for the evaluation of the correlations between the different studied study parameters.

\section{Results}

\subsection{Evaluation of the variability of physicochemical parameters}

Ambient temperature varies from $26.410 \pm 1.230{ }^{\circ} \mathrm{C}$ (station 2) to $28.500 \pm 0.987^{\circ} \mathrm{C}$ (station 4) (Table 1). Surface water temperature varies from $25,800 \pm 0,154{ }^{\circ} \mathrm{C}$ (station 3) to $26,400 \pm 1,121{ }^{\circ} \mathrm{C}$ (station 6). Total dissolved solids concentration ranges from 15,200 $\pm 6,120 \mathrm{ppm}$ (Station 1) to 22,160 $\pm 12,150 \mathrm{ppm}$ (Station 7). Electrical conductivity varies from $22.290 \pm 11.150 \mu \mathrm{S} / \mathrm{cm}$ (station 4) to $29.130 \pm 12.250 \mu \mathrm{S} / \mathrm{cm}$ (station 6 ). $\mathrm{pH}$ varies from $6.550 \pm 0.060$ (station 1) to $6.810 \pm 0.160$ (station 5). Dissolved oxygen ranged from $3.540 \pm 2.210 \mathrm{mg} / \mathrm{L}$ (station 1 ) to $5.520 \pm 1.300$ $\mathrm{mg} / \mathrm{L}$ (station 5). Nitrates range from $0.810 \pm 0.650 \mathrm{mg} / \mathrm{L}$ (station 7) to $1.550 \pm 0.900 \mathrm{mg} / \mathrm{L}$ (station 3). Total Phosphorus range from $0.015 \pm 0.005 \mathrm{mg} / \mathrm{L}$ (station 1) to $0.232 \pm 0.012 \mathrm{mg} / \mathrm{L}$ (station 2). Biological oxygen demand ranges from $0.210 \pm 0.016 \mathrm{mg} / \mathrm{L}$ (station 5) to $0.840 \pm 0.267 \mathrm{mg} / \mathrm{L}$ (station 6). Water velocity ranges from $0.270 \pm 0.300$ $\mathrm{m} / \mathrm{s}$ (station 5) to $0.360 \pm 0.300 \mathrm{~m} / \mathrm{s}$ (station 2). Depth of the stream varies from $10,000 \pm 7,000 \mathrm{~cm}$ (station 2 ) to 42,000 $\pm 15,000 \mathrm{~cm}$ (station 7).

\subsection{Station typology (PCA)}

Correlation circle along the F1×F2 factorial axes (56.01\% of inertia) brings together 9 physicochemical parameters of the study site. F1 axis (31.56\%) opposes the positive variables: water temperature, BOD5, conductivity, dissolved oxygen and total dissolved solids to negative variables: ambient temperature, $\mathrm{pH}$, nitrates and total phosphorus. Even, F2 axis (24.45\% of inertia) opposes the positive variables: conductivity, dissolved oxygen, total dissolved solids, ambient temperature, $\mathrm{pH}$, nitrates, and total phosphorus to the negative variables: $\mathrm{BOD}_{5}$ and water temperature (Fig. 2).

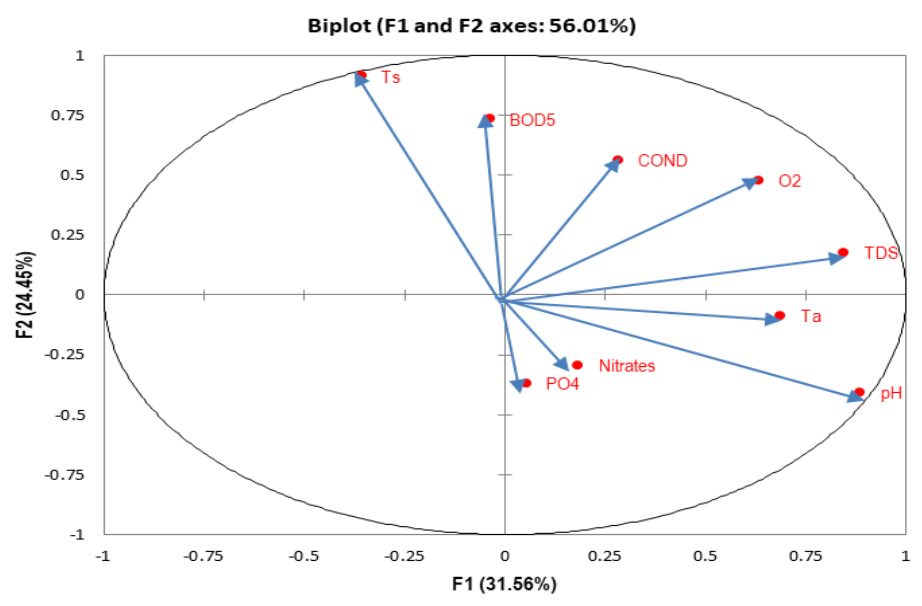

Figure 2 Circle of correlation between physicochemical parameters $(\mathrm{Ta}=$ ambient temperature, $\mathrm{Ts}=$ water temperature, Cond = conductivity, TDS = total dissolved solids, BOD5 = biological oxygen demand, P04 = total phosphorus, $\mathrm{O} 2$ = dissolved oxygen and $\mathrm{pH}=$ hydrogen potential). 
Table 1 Mean values of some physicochemical parameters of the study stations.

\begin{tabular}{|c|c|c|c|c|c|c|c|}
\hline \multirow[b]{2}{*}{ Parameters } & \multicolumn{7}{|c|}{ Stations } \\
\hline & 1 & 2 & 3 & 4 & 5 & 6 & 7 \\
\hline $\mathrm{Ta}\left({ }^{\circ} \mathrm{C}\right)$ & $26.500 \pm 1.010$ & $26.410 \pm 1.230$ & $27.060 \pm 1.120$ & $28.500 \pm 0.987$ & $27.780 \pm 0.123$ & $27.040 \pm 1.010$ & $26.750 \pm 1.210$ \\
\hline Ts $\left({ }^{\circ} \mathrm{C}\right)$ & $26.100 \pm 0.023$ & $26.010 \pm 0.871$ & $25.800 \pm 0.154$ & $25.850 \pm 1.871$ & $26.000 \pm 1.098$ & $26.400 \pm 1.121$ & $25.980 \pm 0.989$ \\
\hline TDS (ppm) & $15.200 \pm 6.120$ & $17.800 \pm 12.210$ & $20.600 \pm 7.650$ & $19.780 \pm 6.050$ & $21.380 \pm 11.450$ & $19.830 \pm 9.330$ & $22.160 \pm 12.150$ \\
\hline $\mathrm{EC}(\mu \mathrm{S} / \mathrm{cm})$ & $23.600 \pm 13.560$ & $25.560 \pm 15.340$ & $26.800 \pm 20.430$ & $22.290 \pm 11.150$ & $28.010 \pm 17.450$ & $29.130 \pm 12.250$ & $23.230 \pm 16.400$ \\
\hline $\mathrm{pH}$ & $6.550 \pm 0.060$ & $6.690 \pm 0.120$ & $6.760 \pm 0.080$ & $6.790 \pm 0.780$ & $6.810 \pm 0.160$ & $6.610 \pm 0.780$ & $6.680 \pm 0.150$ \\
\hline $\mathrm{DO}(\mathrm{mg} / \mathrm{L})$ & $3.540 \pm 2.210$ & $4.410 \pm 1.600$ & $3.620 \pm 2.510$ & $4.050 \pm 2.500$ & $5.520 \pm 1.300$ & $4.670 \pm 2.010$ & $3.980 \pm 1.750$ \\
\hline $\mathrm{NO}_{3}(\mathrm{mg} / \mathrm{L})$ & $1.080 \pm 0.120$ & $0.990 \pm 0.540$ & $1.550 \pm 0.900$ & $0.870 \pm 0.340$ & $1.210 \pm 1.050$ & $1.020 \pm 0.150$ & $0.810 \pm 0.650$ \\
\hline $\mathrm{PO}_{4}(\mathrm{mg} / \mathrm{L})$ & $0.015 \pm 0.005$ & $0.232 \pm 0.012$ & $0.062 \pm 0.025$ & $0.074 \pm 0.055$ & $0.084 \pm 0.056$ & $0.021 \pm 0.006$ & $0.079 \pm 0.055$ \\
\hline $\mathrm{BOD}_{5}(\mathrm{mg} / \mathrm{L})$ & $0.230 \pm 0.015$ & $0.320 \pm 0.055$ & $0.250 \pm 0.015$ & $0.540 \pm 0.056$ & $0.210 \pm 0.016$ & $0.840 \pm 0.267$ & $0.540 \pm 0.125$ \\
\hline Water velocity $(\mathrm{m} / \mathrm{s})$ & $0.310 \pm 0.250$ & $0.360 \pm 0.300$ & $0.310 \pm 0.210$ & $0.310 \pm 0.150$ & $0.340 \pm 0.300$ & $0.270 \pm 0.110$ & $0.320 \pm 0.250$ \\
\hline Depth of the stream $(\mathrm{cm})$ & $30.000 \pm 5.000$ & $10.000 \pm 7.000$ & $30.000 \pm 10.000$ & $30.00 \pm 15.000$ & $32.000 \pm 9.000$ & $15.000 \pm 10.000$ & $42.000 \pm 15.000$ \\
\hline
\end{tabular}




\subsection{Spatial variation of stations according to physicochemical parameters}

Analyze of the main component of the stations according to the physicochemical parameters shows 3 groups (Fig. 3):

- group I: formed stations 1,2 and 4 subjected to the influence of nitrates, total phosphorus and pH;

- group II: formed from stations 3 and 6 subjected to the influence of the biological oxygen demand and the water temperature;

- group III: formed of stations 5 and 7 subjected to the influence of conductivity, dissolved oxygen, salinity and total dissolved solids.

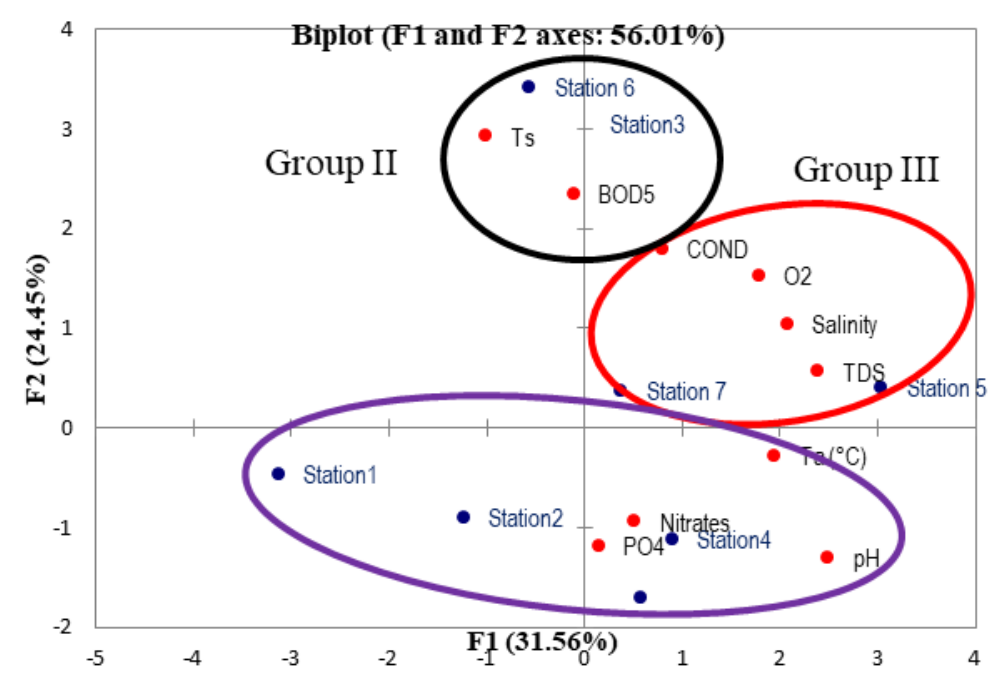

Figure 3 Spatial correlation of the stations according to physicochemistry parameters $(\mathrm{Ta}=$ ambient temperature, $\mathrm{Ts}$ $=$ water temperature, Cond $=$ conductivity, $\mathrm{TDS}=$ total dissolved solids, $\mathrm{BOD}_{5}=$ biological oxygen demand, $\mathrm{PO}_{4}=$ total phosphorus, $\mathrm{O}_{2}=$ dissolved oxygen and $\mathrm{pH}=$ hydrogen potential).

\subsection{Floristic richness of phytoplankton}

Phytoplanktonic floristic richness is raised to 6 classes divided into 28 genera and 34 species. The most represented class is that of Chlorophyceae (12 species) with a proportion of $36 \%$ (Fig. 4). The least represented class is that of Ulvophyceae ( 1 species) with a proportion of $1 \%$. Chlorophyceae appear to be the most important in all stations except Station 4, where Cyanophyceae and Euglenophyceae gain the upper hand with 35\% each.

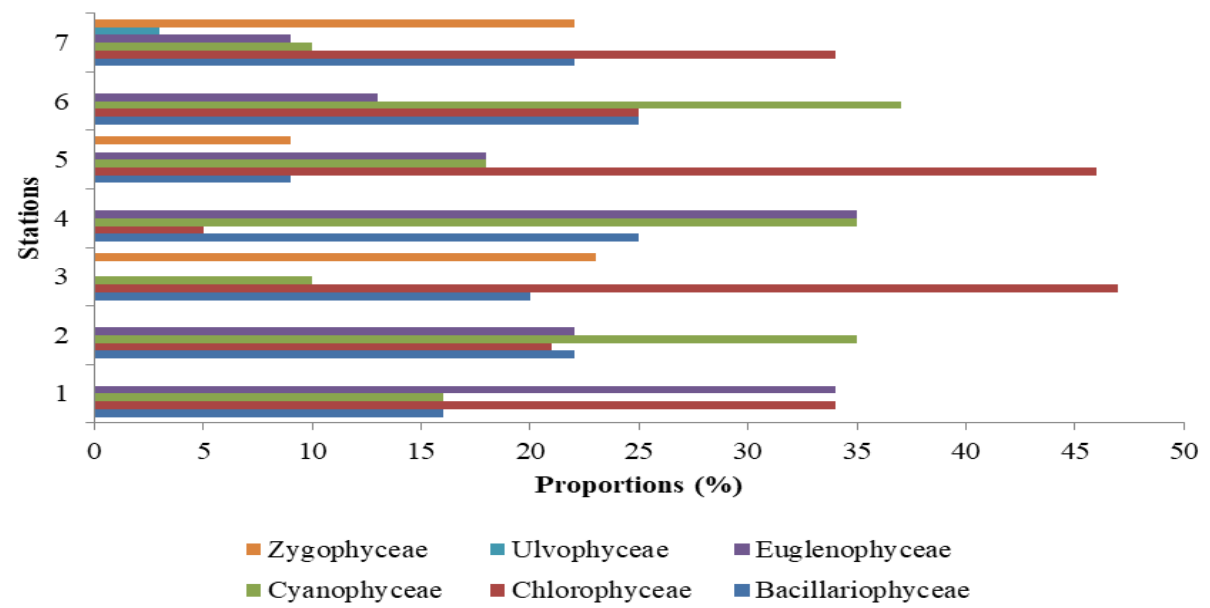

Figure 4 Proportions of the different classes by station and study site. 


\subsection{Specific diversity indices}

Shannon-Weaver diversity index ranges from 3.24\% (stations 7) to 2.02\% (station 1). Regularity of Pielou varies from $0.93 \%$ (stations 7) to $0.78 \%$ (station 1) (Table 2).

Table 2 Shannon-Weaver diversity index and Pielou's regularity

\begin{tabular}{lllllllll}
\hline & \multicolumn{1}{l}{ Stations } \\
\cline { 2 - 8 } Diversity indices & $\mathbf{1}$ & $\mathbf{2}$ & $\mathbf{3}$ & $\mathbf{4}$ & $\mathbf{5}$ & $\mathbf{6}$ & $\mathbf{7}$ \\
\hline Shannon-W (H') & 2,02 & 2,19 & 2,69 & 1,76 & 3,00 & 3,20 & 3,24 \\
Pielou (R) & 0,78 & 0,63 & 0,77 & 0,58 & 0,64 & 0,74 & 0,93 \\
\hline
\end{tabular}

\subsection{Phytoplanktonic abundance}

Calculation of the density of the different species shows that Chlorophyceae are abundant at all stations with the maximum at station 2 (63\%) (Fig. 5). Ulvophyceae are found only at Station 7 with a low density of $9 \%$.

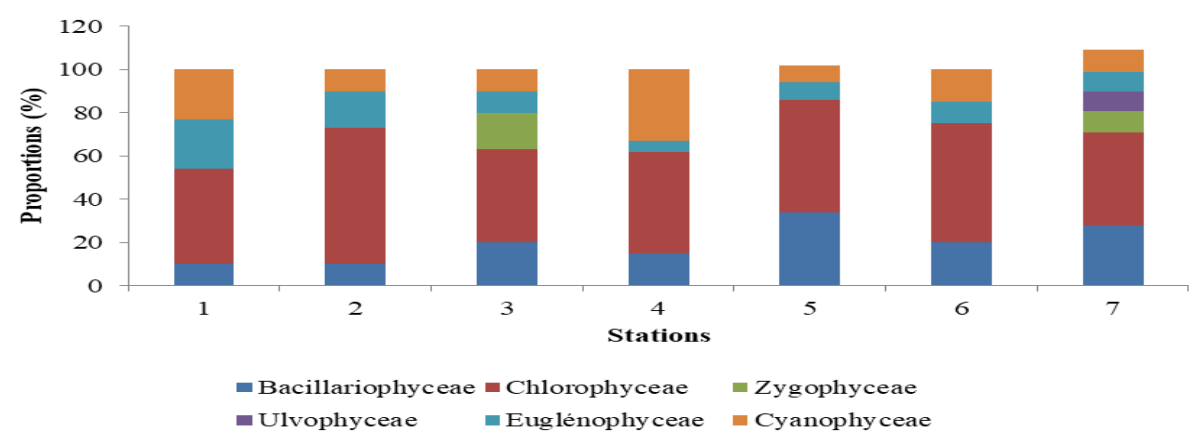

Figure 5 Density of different families based on study stations.

\subsection{Sorensen's similarity index}

Similarity is respectively high between stations 1 and 7, and stations 2 and 6 of 0.44 . It is low between stations 1 and 5 of 0.16 (Table 3).

Table 3 Similarity index between the stations of the study site.

\begin{tabular}{llllllll}
\hline Stations & $\mathbf{1}$ & $\mathbf{2}$ & $\mathbf{3}$ & $\mathbf{4}$ & $\mathbf{5}$ & $\mathbf{6}$ & $\mathbf{7}$ \\
\hline 1 & 1 & & & & & & \\
2 & 0,18 & 1 & & & & & \\
3 & 0,12 & 0,20 & 1 & & & & \\
4 & 0,31 & 0,33 & 0,26 & 1 & & & \\
5 & 0,16 & 0,36 & 0,28 & 0,31 & 1 & & \\
6 & 0,17 & 0,44 & 0,20 & 0,50 & 0,20 & 1 & \\
7 & 0,44 & 0,23 & 0,24 & 0,31 & 0,33 & 0,35 & 1 \\
\hline
\end{tabular}

\subsection{Spatial variability of species by major groupings}

The F1×F2 axes (97.21\% of inertia) of the correspondence factor analysis (CFA) identify two groups of stations according to the species that are exclusive to them (Fig. 6). Group I recalls stations 1, 2 and 3 by the species that are exclusive to them: Prorocentrum micans, Pleurotaenium trabecula, Rhodomonas sp., Cymbella frustule, Cymbella ventricosa, Chlamidomonas globosa, Aphanizomenon sp., Trachelomonas lefervrei. Group II recalls stations 5, 6 and 7 by the species that are exclusive to them: Micrasterias truncata, Gonatozygon pilosum, Limnothrix sp., Phacus sp. Station 4 is a station isolated from the others. She does not have an exclusive species. 


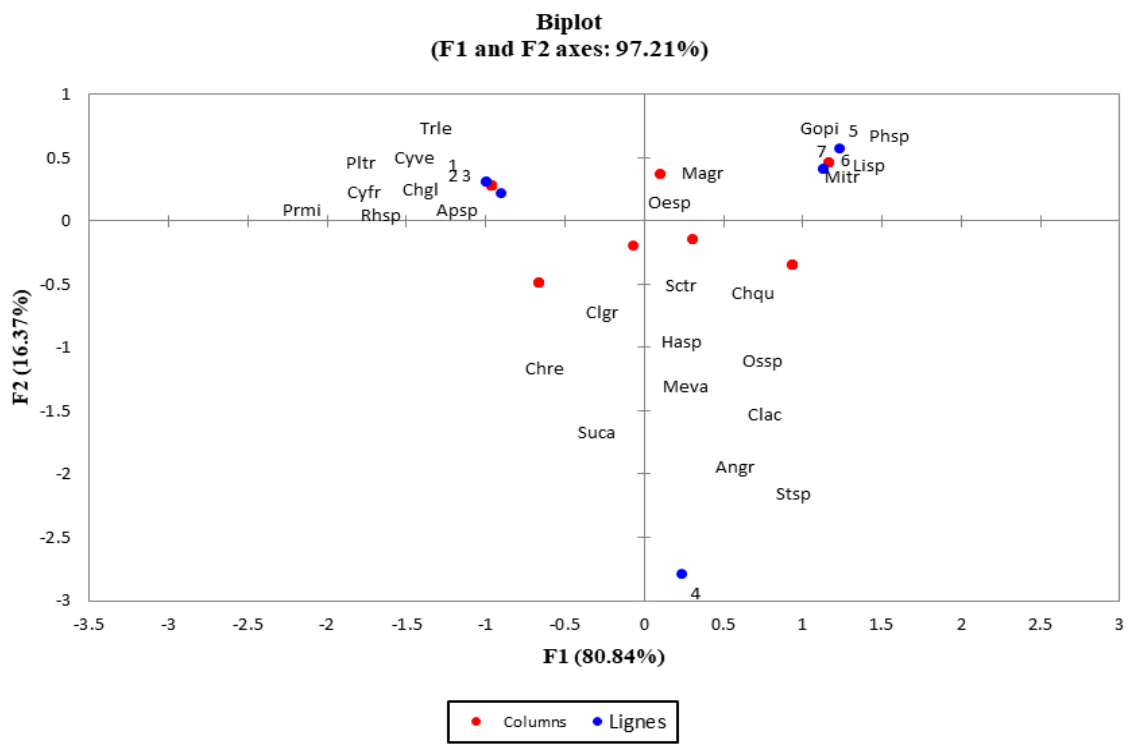

Figure 6 Correlation of Study Stations by Species

$($ Magr $=$ Mastrome gracile, Prmi $=$ Prorocentrum micans, Chqu $=$ Chodatella quadriseta, Clac $=$ Closterium aciculare, Stsp $=$ Striatella sp., Pltr $=$ Pleurotaenium trabecula, $\mathrm{Rhsp}=$ Rhodomonas $\mathrm{sp}$. , Meva $=$ Melosira varians, $\mathrm{Cyfr}=$ Cymbella frustule, Mitr $=$ Micrasterias truncata, Gopi $=$

Gonatozygon pilosum, Suca $=$ Surririela capronii, Cyve = Cymbella ventricosa, Hasp $=$ Haematococcus sp., Chgl $=$ Chlamidomonas globosa, Sctr $=$ Scrippsiella trochodea, Lisp = Limnothrix sp., $\mathrm{Phsp}=$ Phacus sp., $\mathrm{Clgr}=$ Closterium gracile, Angr $=$ Ankistrodesmus gracilis, Syaq $=$ Synechocystis aquatilis, Tafl $=$ Tabellaria flocculosa, Stae $=$ Stigeoclonium aestivale, Apsp $=$ Aphanizomenon sp., Trle $=$ Trachelomonas lefervrei, Oesp $=$ Oedogonium sp., Chre = Chlamidomonas reinhardti, Ossp = Oscillatoria sp.).

\section{Discussion}

Analyze of physicochemical parameters shows that nitrates and total phosphorus vary from one station to another. The Principal component analysis confirms the spatial variation of the stations according to the physicochemical parameters which show that the nitrates and total phosphorus have a high content upstream (station 1, station 2, station 4) and low downstream; which shows that Batika would be a self-purifying river. These results are shared by Makhoukh [24] who has shown that the presence of upstream and downstream effluents in the waters of Oued Moulouya in Morocco is due to the self-purification capacity of the watercourse. $\mathrm{pH}$ resulting from the sampling of the watercourse meets the prescribed standards (between 6.5 and 7.5). These $\mathrm{pH}$ values between 6 and 7 would indicate the good quality of the waters and the low presence of anthropogenic activities that could lead to water degradation. These results are similar to those of Motto [25] in Londji where $\mathrm{pH}$ values vary between 6 and 7 determinants of a rich biodiversity environment. The waters of the Batika river would be of good quality for the development of aquatic biodiversity. Suspended matter affects the transparency of the water and reduces the penetration of light and, subsequently, photosynthesis. The Batika river with its fast flow regime carries the suspended matter that would influence growth, which is a function of photosynthesis.

The Dissolved oxygen in surface water comes mainly from the atmosphere and, the photosynthetic activity of algae and aquatic plants [26]. According to the defined water quality standards, water is of very good quality when the dissolved oxygen is greater than $5 \mathrm{mg} / \mathrm{L}$ [27]. In this study dissolved oxygen ranged from 3.98 to 5.52 . The low 3.98 value of oxygen obtained would be justified either by the importance of animal biodiversity consuming dissolved oxygen in water and by the low diversity of photosynthetic species in the water. Electrical conductivity is a numerical expression of the ability of a solution to conduct electrical current. Most mineral salts in solution are good conductors. On the other hand, organic compounds are bad conductors [26]. Conductivity is variable of 44.25 and $58.25 \mu \mathrm{S} / \mathrm{cm}$. It is positively correlated with salinity and TDS and describes a growing dissolved salt gradient in the environment and confirms that the waters of the Batika river would be good conductors of electrical current [28]. The dissolved nutrients nitrates and phosphates are poorly represented. In the same vein, Biological Oxygen Demand (BOD 5 ) is a function of organic matter and depends on nutrient salts. The concentrations of nitrates and phosphates are therefore important parameters for monitoring the quality of surface water. Excess intake of nutrients causes an explosion of phytoplankton. Situation is very critical from a concentration of more than $3 \mathrm{mg} / \mathrm{L}$ of nitrites [26]. In the Batika river, nitrates and total phosphorus confirm the oligotrophic character of the nutrient-poor environment. 
The Phytoplanktonic communities consist of assemblages of species with very different morphological and physiological characteristics, the organization of which is an essential component in understanding the functioning of an ecosystem. Knowledge of the taxonomic composition of stands is a necessary source of information. Indeed, the identification of phytoplanktonic communities makes it possible to establish real tools for diagnosis and assessment of pollution, such as diatomic indices [1]. At the Batika river, Prokaryotes (Cyanophyceae) and Eukaryotes (Chlorophyceae, Euglenophyceae and Bacillariophyceae) are represented. In terms of abundance Chlorophyceae (36\%) are more represented. These results differ from those found by Motto [25] where Bacillariophyceae are more represented (59.67\%) in Londji River in Kribi. This relative abundance of Chlorophyceae indicates that the environment is less polluted.

The Number of species recorded (34 species) is lower than those obtained by other authors, and therefore 170 species for Lung'Ayia et al., cit. Ba [29] and 174 species Huszar et al., cit. Ba [29] in the tropics. Motto [25] lists 124 species in the Londji river in Kribi. Dibong and Ndjouondo [23] recorded 105 species in the Kambo and Longmayagui rivers in Douala. According to Ndjouondo et al. [3], species diversity would allow for a high degree of stability in the functioning of the ecosystem in the face of environmental disturbances. However, Batika is an undisturbed hydrosystem. The low species diversity is explained by the very high current velocity, which does not favor the multiplication of species, and the bottom substrate composed of associated sand rocks.

The Shannon-Weaver index varies between 1.76 and 3.24. These values being less than 4 confirm the low phytoplanktonic diversity. This result justifies the results of Kemka et al. [8], which states that a poorly diversified phytoplanktonic community has pioneer stands characterized by a low number of high-status species. These results are consistent with those obtained at the Batika river. Regularity close to 1 justifies the stability of the community. This result is close to the works of Motto [25] who found a stability of the community between the values 0.8 and 0.9 . The values of $\mathrm{H}^{\prime}$ reveal a medium undisturbed by pollution. Batika would then be a less polluted stream with a poorly diversified but stable phytoplanktonic community. The differences between the stations would come from the presence of micro habitats along the Batika river. Nguetsop et al. [30] have shown in the Foto and Nkong-ni sites that the composition of macrophytes could influence the physicochemical composition and consequently that of phytoplankton. The Distribution of phytoplankton would be influenced by that of macrophytes.

\section{Conclusion}

This study at the Batika river has helped to inform knowledge of its ecological situation. For this purpose, 7 stations were adopted and studied, 2 groups were observed according to the physicochemical parameters made up of exclusive species. Group I bringing stations 1, 2 and 3 upstream together; group II bringing stations 5, 6 and 7 downstream closer together. Station 4 is considered a transition station between upstream and downstream. Six classes of algae were inventoried in the Batika river divided into 28 genera and 34 species. The Class of Chlorophyceae (36\%) is the most abundant. Diversity of Shannon varies between 1.76 (station 1) and 3.24 (stations 7). The Batika river is a less polluted stream with a poorly diversified, stable and less toxic phytoplanktonic community. This character would justify a young population with a high multiplication power with predominance of a small number of species. This river would be favorable for the conservation of carp fry.

\section{Compliance with ethical standards}

\section{Acknowledgments}

We thank the Laboratory of Botany of The University of Douala for having put the material at our disposal.

\section{Disclosure of conflict of interest}

There is no conflict of interest.

\section{References}

[1] Ndjouondo GP, Ba'ana Etoundi ML, Nwamo RD, Fankem H and Dibong SD. (2017). Analysis compared the water quality of the Kambo and Longmayagui rivers (Douala) from diatom biological indices. International Journal of Innovation and Scientific Research, 33(1), 45-55.

[2] Bourrelly P. (1966). Freshwater algae: green algae. N. Boubee and Co., Paris, 61-65. 
[3] Ndjouondo GP, Ba'ana Etoundi ML, Nwamo RD, Fankem H and Dibong SD. (2017). Structure and dynamics of the periphytic algae of the rivers Batika (Yabassi) and Tongo'o Bassa (Douala). International Journal of Innovation and Scientific Research, 32(2), 329-344.

[4] Lazzaro X. (1981). Ecological Experience on the Water Quality of the Dakar-Bango Reservoir, source of drinking water for the city of Saint-Louis, Senegal. Video reportage interview of 2'45", Canal IRD, www.ird.fr/lamediatheque.

[5] Iltis A and Compere P. (1974). Seaweed from the Lake Chad region. 1. General characteristics of the middle. ORSTOM. ser. Hydrobiol., 11, 3-4.

[6] Groga N. (2012). Structure, Functioning and Dynamics of Phytoplankton in Ta'abo Lake (Ivory Coast). PhD thesis, University of Toulouse, 160-200.

[7] Margalef R. (1960). Indicator value of the composition of phytoplankton pigments on the productivity, taxonomic composition and dynamic properties of populations. Comm. Int. Tells me, 15, 277-281.

[8] Kemka N, Njine T, Zebaze TSH, Niyitegeta D, Nola M and Menbohan F. (2004). Phytoplankton of the Yaounde Municipal Lake: ecological succession and stand structure. Water Science Journal, 17(3), 301-316.

[9] MINEPAT. (2011). Quarterly activity report. Report, Provincial Delegation/MINEPAT, Cameroon, Yabassi, 6-69.

[10] Meva'a AD, Fouda M, Bonglam CZ and Kamwo M. (2010). Spatial Risk Analysis flood in the Mbanya watershed in Douala, the economic capital of Cameroon. Report, NOVATECH, The University of Douala, 1-10.

[11] INC. (2011). Departmental Monograph of Nkam. Report, INC, Yabassi, 30-201.

[12] MINADER. (2012). Quarterly activity report. Report, Provincial Delegation/MINADER, Cameroun, Yabassi, 10-66.

[13] OFEV. (2007). Methods of analysis and assessment of rivers. Diatom level (Region), FOEN, Berne, 2-150.

[14] Bourrelly P. (1968). Freshwater algae: yellow and brown algae. N. Boubee and Co., Paris, 50-55.

[15] Bourrelly P. (1970). Freshwater algae: blue and red algae. N. Boubee and Co., Paris, 66-77.

[16] Compere P. (1967). Seaweed from the Sahara and Lake Chad regions. Bull. Jard. Bot. Nat. Belgium, 37(2), 109288.

[17] Compere P. (1974). Seaweed from the Lake Chad region. II Cyanophyceae. ORSTOM., ser. Hydrobiol., 8(3-4), 165198.

[18] Compere P. (1976). Seaweed from the Lake Chad region. VI. Chlorophycophyta (2nd part: Ulotrichophyceae, Zygnemataceae). ORSTOM., Ser Hydrobiol., 10(3), 135-200.

[19] Gronblad R, Prowse GA and Scott AM. (1958). Sudanese Desmids. Acta Botanica Fennica, 58, 1-82.

[20] Krammer K and Lange-Bertalot H. (2000). Bacillariophyceae. In: Ettl H, Gerloff J, Heynig H and Mollenhauer D (Eds), Susswasserflora von Mitteleuropa. Spektrum Akademischer Verlag, Heidelberg, Berlin, 1-5.

[21] Iltis A. (1980). Algae. In: Durand JR and Leveque C (Eds), Flora and aquatic wildlife of Sahelo - Sudanese Africa. ORSTOM, initiation collection, technical documents $n^{\circ} 44$, Paris, 9-61.

[22] Guiry MD and Guiry GM. (2020). AlgaeBase. World-wide electronic publication, National University of Ireland, Galway.

[23] Dibong SD and Ndjouondo GP. (2014). Floristic inventory and Ecology of algae of Kambo and Longmayagui rivers in Douala (Cameroon). JAB, 80, 7147-7160.

[24] Makhoukh M, Sbaa A, Berrahou M and Van C. (2011). Contribution to physicochemical study the surface waters of Oued Moulouya (Eastern Morocco). Larhyss Journal, 9,149-169.

[25] Motto I. (2014). Isolation and characterization of mangrove microalgae associated with shrimp farming. Master thesis, The University of Douala, 5-53.

[26] De Villier. (2005). Physico-chemical quality of surface water: general framework. Report, Institute Brussels for Environmental Management/Environmental Data Observatory: "Water in Brussels", 2-16.

[27] Daniel A and Soudant D. (2009). DCE assessment April 2009 - Quality element: assessment oxygen. Report, Ifremer, 20-73. 
[28] Globe. (2006). Globe, information, measurements, results, results visualization globe, site international, database. www.globe.gov globe-swiss.

[29] Ba N. (2006). The Phytoplankton Community of Lake Guiers (Senegal): Types of Functional Associations and Experimental Approaches to Regulation Factors. Postgraduate PhD Thesis at Cheikh Anta Diop University, Dakar (Senegal), 2-144.

[30] Nguetsop VF. (2009). Status of wetland sites surveyed in the western highlands Cameroon: Water Science Review, 22(1), 15-27.

\section{How to cite this article}

Ndjouondo GP, Muyang RF, Nouck AE, Nwamo RD, Fotso, Tita MA and Dibong SD. (2020). Diversity and ecology of phytoplankton of Batika river (Yabassi, Cameroon). GSC Biological and Pharmaceutical Sciences, 11(2), 204-214. 